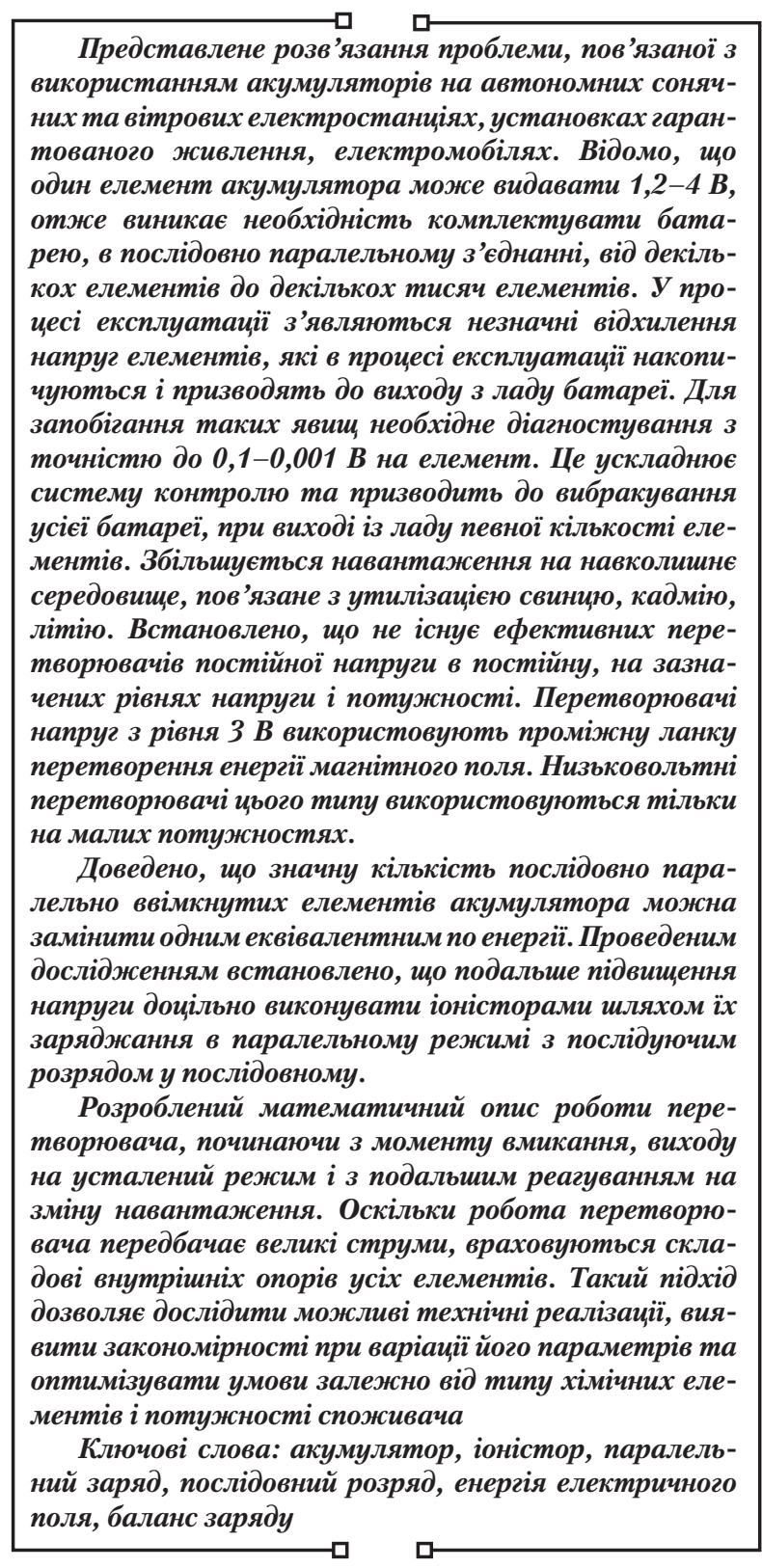

Received date 07.11.2019

Accepted date 11.03.2020

Published date 30.04.2020
UDC 621.314

DOI: $10.15587 / 1729-4061.2020 .198950$

\title{
DEVELOPMENT OF A POWERFUL LOW-VOLTAGE DC CONVERTER FOR SYSTEMS OF ELECTRIC POWER ACCUMULATION
}

\author{
A. Panchenko \\ $\mathrm{PhD}$, Associate Professor \\ Department of Electrotechnical Systems of \\ Arms and Military Equipment* \\ E-mail: martensid1929gmail.com \\ D. Karlov \\ Doctor of Technical Sciences, \\ Head Deputy of Scientific Center \\ Center of Air Force of Scientific Work* \\ E-mail: zeroua108@ukr.net \\ Y u . Kus a kin \\ PhD, Associate Professor, Head of Faculty \\ Faculty of Postgraduate Education* \\ E-mail: kusakin_xxx@ukr.net \\ M. Kuravskiy \\ Researcher \\ Faculty of Anti-Aircraft Missile Troops* \\ E-mail: chris_fehn@meta.ua \\ O. Drol \\ Lecturer \\ E-mail: drolsasha@ukr.net \\ *Ivan Kozhedub Kharkiv University of Air Force \\ Sumska str., $77 / 79$, Kharkiv, Ukraine, 61023
}

Department of Tactics and General Military Disciplines*

Copyright (C) 2020, A. Panchenko, D. Karlov, Yu. Kusakin, M. Kuravskiy, O. Drol This is an open access article under the CC BY license

(http://creativecommons.org/licenses/by/4.0)

\section{Introduction}

Existing chemical energy sources typically have a voltage on one element in the range of $1.2 \mathrm{~V}$ for alkaline and up to $4 \mathrm{~V}$ for lithium. The required voltages and capacities are much higher for the consumption industry. The traditional way is a combination of a series of several elements to several thousand elements in guaranteed power settings and electric vehicles. This leads to known complications in their production and operation. There are no DC-DC converters at the specified voltage and power levels up to $200 \mathrm{~kW}$. This is what forces to combine so many elements. The next problem is to control and manage the number of batteries. Given the properties of lithium batteries in terms of their fire risk, the accuracy of measuring the voltage of

each element should be up to $0.01 \mathrm{~V}$. Therefore, it is important to consider a study aimed at replacing a large number of low-power chemical elements with one equivalent in energy, with a voltage of up to $4 \mathrm{~V}$ by creating a DC-DC converter from $1.2-4 \mathrm{~V}$ to $200 \mathrm{~V}$.

Effective use of electricity is possible only in the presence of systems of its accumulation. It is known that electricity levels vary dramatically depending on the day, season, and other factors. The rapid development of wind and solar power further complicates the unpredictability of electricity flows. The only way out is to create storage systems. Chemical energy stores have become widespread. However, they need an extremely complex control system as the number of elements grows. Failure of $10 \%$ to $20 \%$ of the batteries causes the entire battery to be found defective. 


\section{Literature review and problem statement}

Chemical sources of electrical energy as capacitors have been widely used in both industrial and domestic energy fields. Problems related to energy accumulation and network return were investigated in [1,2], which shows the feasibility of using megawatt battery stations in conjunction with wind. However, the paper did not address the operation of several thousand chemical elements with an element voltage up to $1.2-3 \mathrm{~V}$. The use of flow batteries for powerful energy systems is the most expedient from the point of view of the authors [3, 4], but there are difficulties with the energy derivation. This may be due to the instability of the chemical composition of the components and other conditions. The authors proposed a number of mathematical models that, in their opinion, would help find the best battery life depending on the mode of operation. At the same time, the features of power redistribution between charge and discharge elements of chemical batteries were not taken into account. Similar problems occur with lower capacities, for example in guaranteed power systems. This applies to studies conducted at hybrid wind and solar power plants using an electrical energy storage system. In particular [5] compared the use of capacitors, batteries, and flow batteries. In the studies, the issues of optimizing multifactor problems by different mathematical methods were solved, and in-depth tests on a vanadium-cerium battery for peak loads were also performed in [3]. Those papers did not cover the question of the structure of the combination of chemical sources. In their simulations, the works did not take into account the fact that a chemical battery consists not of one element but of many hundreds and sometimes thousands of elements. In [6], tests were performed on lithium batteries while comparing field data with model data obtained from Matlab Simulink. However, the Simulink environment uses simplified standard models, at least battery-based, that do not take into account the features of different power sources. The study of the combined work of a solar station and a battery system was proposed in [7] for electric vehicle service networks. Dynamic battery modes were considered in a Simulink environment, which was not appropriate.

Possibilities of using an ionistor accumulator (also called the molecular accumulator, or supercapacitor) were studied in [8]. It was not mentioned, however, that its permissible voltage for the element was also $3-4 \mathrm{~V}$; therefore, it had to be combined with a connection, which would complicate the control system. The system of combining solar stations for charging electric vehicles with lithium batteries, presented in [9], was based on the Simulink environment, which may be doubtful, especially in transients. In [10], it was proposed to solve the problem of unbalance of lithium battery elements, in the course of charge-discharge cycles, by the method of parallel switching. Since these are special-purpose submarines, where cost is not crucial, the method is possible but burdensome for mass production.

The problem can be described as the progressive instability of the battery element parameters in the charge-discharge process. The discrepancy of these parameters over time accumulates. Its effect on the battery life and complexity of the solution were highlighted in [11]. Lead-acid batteries were considered, the required measurement accuracy was $10 \mathrm{mV}$ per element, and the active and passive balancing systems were compared. However, this approach does not solve the main issue of the number of elements and the need for elemental control.

Considering that the voltage of each element cannot be more than $4 \mathrm{~V}$, the battery should be $100-200 \mathrm{~V}$, and the number of elements in a parallel connection series can reach thousands. At the same time, each element of the battery has slight deviations already at the production stage, capacity, voltage, internal resistance, and resistance of switching buses. Typically, the deviation of the parameters by one hundred percent of the value causes a change of currents in the hundreds of amps. This is due to the facts that the internal resistances are thousandths of ohms $(\Omega)$ and the electromotive force is $2-5 \mathrm{~V}$. As a result, the parallel connection of the battery elements causes equalizing currents, and the serial connection disrupts the proportional voltage distribution.

In the course of exploitation, the differences inevitably increase, and the distinctions caused by the temperature differences grow. Active and passive balancing systems improve the situation somewhat, but it happens due to the fact that the lagging elements receive additional energy and the better ones are converted to the passive state. In the subsequent charge cycles, the situation is repeated until complete degradation of the lagging element. As a result, the battery life of such elements will be substantially shorter than that of a single element. With regular deep discharges, after some time, the exponential growth of the failures of the individual elements begins. All of these problems can probably be solved by replacing the multi-element battery with an energy-equivalent element.

One of the specific properties of electricity is the need for its immediate use. In the case of a misbalance of generation and consumption, an emergency situation arises. The amount of losses depends on the amount of unused electricity. Therefore, taking into account the cost of energy, various directions of its storage and subsequent return to the consumer are developing rapidly. One way to accumulate electricity is to use chemical energy storage devices. The problem is common for both a standalone solar or wind power plant several kilowatts of power and for a megawatt power system. It is difficult to cover all the variety of electrochemical groups used, but the main ones are cadmium, lead, lithium, and vanadium (for flow batteries). This series also includes fuel elements $[12,13]$. All this diversity is combined by only one parameter - their output voltage is in the range of $0.7-4 \mathrm{~V}$. For low power consumers of $10-100 \mathrm{~W}$ there are DC-DC converters, but with an input voltage of $5 \mathrm{~V}$ and above, up to $500 \mathrm{~W}$ of $8 \mathrm{~V}$ or greater, $12-24 \mathrm{~V}$ for stand-alones, and $100-400 \mathrm{~V}$ for industrial output.

Today, the solution for the whole power range of $500 \mathrm{~W}$ to $100 \mathrm{MW}$ is also single - to combine a series of elements in parallel. The number of elements is from 6 to 12 in a car and up to several thousand in the guaranteed power supply of industrial power systems and electric vehicles. It should be noted that any group of batteries, such as lead, is branched into a huge number of subgroups, distinguished by metal additives and structural design, each for their own purposes [14]. The same pattern applies to other groups of batteries $[15,16]$. In general, a control system can be created for any battery group or subgroup. However, this is not enough; given the toxicity of certain electrolytes, the explosiveness and fire hazard of some batteries must be monitored individually. In some cases, this cannot be done separately, so elements are divided into groups and control is carried out in sections [17]. 
The global problem in this situation is as follows. During the release of any battery, each of its 'jars' has close parameters in terms of internal resistance, open circuit voltage, the ratio, and distribution of active masses. Already after the first discharge, these indicators are 'diverging' in each of the elements, each battery is discharged in its own way, and their control system is shared. As a consequence, the next charge does not start with the same conditions, and these deviations accumulate during operation. For lithium batteries, the critical parameter is temperature, with measurement accuracy of up to tenths of a degree (fire and explosion), and it also becomes different. That is, the system of chemical storage management becomes extremely complex, whereas its reliability must be better. One striking example is the incident at the Salyut-7 space station, which was deactivated due to a false positive of the battery level sensor, which showed $100 \%$ charge [18].

The situation is complicated by the fact that when one or two cans of all lead accumulators and up to $10-15 \%$ lithium accumulators fail, the battery is discarded. In some countries, lead-acid batteries have been recycled, the issue on lithium ones has not been resolved, and only nickel and cobalt extraction technologies have been developed. In Europe, currently, only $5 \%$ of lithium batteries are recycled [19] and only $10-20 \%$ of them are unusable.

The authors propose, instead of a certain number of consecutively switched elements, to install one equivalent in power with the corresponding voltage. Advantages in the control system, reliability, safety, and efficiency of charge and discharge processes are obvious. The reliability of information as of the source, and, therefore, the reparability, is increasing.

High voltage step-down DC-DC converters are widely used in the world. However, there are some difficulties with boost converters. In particular, converters with power up to $40-50 \mathrm{~W}$ from $2-4 \mathrm{~V}$ voltage, $1 \mathrm{~kW}$ from $8-9 \mathrm{~V}$, as well as $3 \mathrm{~kW}$ from $48 \mathrm{~V}$ and above have been used [20-22]. It is problematic to create a boost converter with a voltage of $0.8-5 \mathrm{~V}$ and with a power exceeding $10 \mathrm{~kW}$. This is probably what prompted them to go in parallel with chemical power supplies.

There are several reasons for this. According to [23], at low-voltage currents with currents exceeding $100 \mathrm{~A}$, the static losses in semiconductors are by an order of magnitude greater than dynamic ones. Therefore, the power circuits should include a minimum of semiconductor elements and a power transformer. The second factor is the excess energy stored in the inductance of the scattering. In [23], a charge-converter was considered, but such a solution requires an additional voltage stabilizer, which significantly reduces the efficiency with voltages exceeding $10 \mathrm{~V}$. According to $[24,25]$, non-inductive voltage converters with $0.9-1.8 \mathrm{~V}$ have been worked out, with $90 \%$ efficiency but at up to $10-20 \mathrm{~W}$. Due to the limited amount of energy, this type of converters is not widespread because of the limited amount of energy that the capacitor can transmit. In the literature, they have several names: the converter with the pumping of the capacitor, with charge transfer, and with the switching of capacitors. The emergence of an ionistor gives the opportunity to transmit much more energy.

The authors have studied a $0.9-5$ VDC ionistor converter to a voltage greater than $200 \mathrm{~V}$ without the use of inductive elements. This was made possible by combining the properties of chemical energy storage devices with voltages up to $5 \mathrm{~V}$ and ionistors with similar voltages. Both the first and second elements have no energy storage constraints.

\section{The aim and objectives of the study}

The aim of the study is to develop a method of increasing the low-voltage direct current of a chemical energy capacitor without the use of induction elements, i. e., without intermediate conversion of magnetic field energy.

To achieve this aim, the following objectives were set and done:

- to determine the feasibility of using a DC-DC converter from voltage levels of 1-5 V, with electromagnetic energy conversion;

- to find out the capacity of ionistors to carry out direct conversion of low-voltage DC electric energy;

- to get a mathematical model of the work of an ionistor converter and to find out the regularities of its operation with variation of parameters.

\section{Materials and methods of the research}

In the first stage, the fundamental possibility of the very idea of capacitive transformation was investigated. For this purpose, the power scheme presented in Fig. 1. Capacitors and thyristors were used as keys without forced switching. The main indicator was to achieve the effect of a 'transformer' at constant voltage. That is, when increasing the output voltage twice, the output current, relative to the input, decreases twice. The output voltage must be stabilized automatically when the load changes, without additional regulation through the control circuit. The effect on the power of the clock frequency and the ratio of the duration of charge and discharge were also evaluated.

In the second stage, the switch to ionistors and transistor switches was made. This allowed varying frequencies, capacities, and work on different types of ionistors in a wide range. According to the obtained dependences, a comparative characteristic of the capacitor converter and the ionistor was carried out.

The third stage. It was designed to cover a wide range of capacities, from industrial power systems to autonomous wind and solar generation systems. They use a variety of chemical energy storage devices that differ in the amount of energy, in their type, in the number of elements, and in their connection schemes. It is not advisable to carry out converter studies for each individual object. Therefore, a mathematical model was investigated to determine the converter parameters for a particular type of chemical storage and their operating conditions.

\section{Results of studying low-voltage direct current} converters

\subsection{Research on a low-voltage step-up electromag- netic DC-DC converter}

Tests were conducted on the use of serial DC-DC converters. It has been established that at an input voltage of $2-3 \mathrm{~V}$ the maximum power is $10-20 \mathrm{~W}$. Starting from a voltage of $8-10 \mathrm{~V}$, it is not possible to get more than $300 \mathrm{~W}$ as a result of the modular units' upgrading. The use of ad- 
ditional radiators or additional ventilation is ineffective. Switching to voltages above $10 \mathrm{~V}$ increased power up to $500 \mathrm{~W}$, but there were problems with the high-frequency power transformer. During the switching of the power keys, an anti-electromotive force arose due to the inductance of the transformer. To some extent, its impact was reduced by circuit solutions, but with the increase in power, these measures were not effective. The next step was to use sectioned transformer windings. Further research showed that this solution could increase power only to $1-1.5 \mathrm{~kW}$. The solution to the problem of converting direct current electricity up to $4 \mathrm{~V}$ with power exceeding $500 \mathrm{~W}$ by traditional DC-DC converters has proved impossible.

\section{2. A study of a low-voltage direct current ionistor} converter

Known DC-DC converters operate, using an inductive element, transformer or throttle. There is a chain of transformations of energies: direct current into alternating, into energy of the magnetic field, again into alternating current, and rectification. It is extremely problematic to create a high-frequency $(100-300 \mathrm{kHz})$ transformer with a power of $100-200 \mathrm{~kW}$ at an input voltage of up to $5 \mathrm{~V}$. Therefore, the idea of charging a certain number of ionistors in a parallel mode was implemented, followed by a series discharge in a sequential one. In this approach, the low-voltage properties of chemical energy storage and ionistors were organically combined. Fig. 1, $a$ shows a diagram of the converter that was used to study the conditions of double voltage increase. When the control pulses are applied to the $\mathrm{VS}_{1}$ and $V S_{2}$ thyristors, they open and charge in a circle $+G$, $V D_{1}, V S_{1}, C_{1}$, and $-G$, as well as in a circle $G, V D_{1}, C_{2}, V S_{2}$, and $-G$. As the capacitor charge of the thyristors closes, the discharge of capacities $C_{1}$ and $C_{2}$ occurs in successive inclusion in a circle: $+C_{1}, V D_{2}, C_{2}, V D_{3}, C_{3}$, and $-C_{1}$. After a certain number of charge-discharge cycles on the capacitor $C_{3}$ and $R$, the voltage is twice that of the supply voltage $G$. At the moment of discharge of the capacitor, the diode $V D_{1}$ is closed by the total voltage of the capacitors and does not allow discharge through the power source. Similarly, the $V D_{3}$ diode prevents discharge of the $C_{3}$ storage capacitor per power supply circuit.

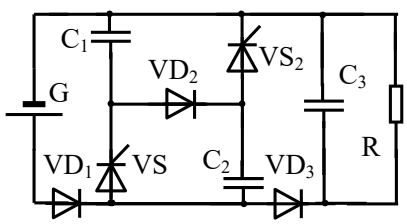

$a$

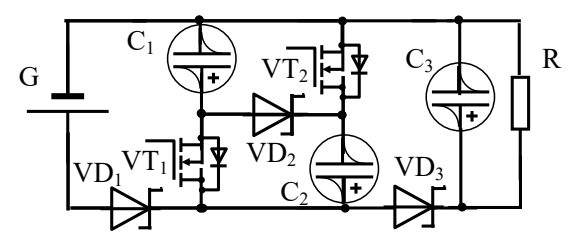

$b$

Fig. 1. An ionistor converter of direct current to direct current: $a-a$ thyristor; $b-a$ transistor

As the load $R$ increases, the discharge capacitance increases and, accordingly, a greater amount of energy is supplied from the source, i. e., there is a self-regulation of voltage twice the output. In order to increase the voltage, a circuit of $n$ parallel capacitors $C_{1}, C_{2}, \ldots C_{n}$ is drawn up $n$ times.

The diagram shows satisfactory operation at power up to $500 \mathrm{~W}$, easy to manage, and the thyristors are locked naturally, at the charge of capacities and reduction of current. For increase of power, it is necessary to use forced switching of the thyristors, which complicates the circuit and worsens the quality of the output voltage by the discharge pulses of the switching capacitor. In general, the thyristor circuitry has some advantages, but as the power grows, the capacitor charge processes become less manageable.

The use of electrolytic capacitors allowed increasing the capacity to kilowatts; its further increase led to their overheating.

The power part of the converter on the ionistors is presented in Fig. 1, $b$. A typical modern ionistor has a capacity of up to 3,000 F [26], serially used as an auxiliary means for starting engines at low temperatures. Since $1-10 \mathrm{kA}$ currents are required to convert significant power at low voltages and high frequencies, the element must have low internal active resistance and low impedance. It is difficult now, without full-scale research, to determine these parameters, since they are significantly frequency-dependent, and the manufacturer does not always specify control frequencies, so these values fluctuate. Specialized ionistors with low internal resistance under the Low ESR marking are used where ion-separator is applied [27]; study [28] specified the technology of their production, for which CNF-PANI material was proposed to ensure significant reduction of internal resistance [29]. Molecular accumulator $24 \mathrm{PP} 30 / 0.003$ with a capacity of $104 \mathrm{~F}$ has an internal resistance of $0.003 \Omega[30]$. According to the data given in [31], the use of liquid organic electrolytes opens new possibilities. Electrolytes with high ion transport properties are required to obtain high-frequency ionistors with low consistent equivalent resistance [32].

That is, there are ways to further reduce the internal resistance of the ionistor, as this parameter can become critical when operating in an ionistor converter.

For the scheme of Fig. 1, $b$, Schottky diodes were used because they operate at low voltages and have a slight voltage drop in the open state of $80-250 \mathrm{mV}$. Alternatively, dual diodes of the STPS120L15TV series of $15 \mathrm{~V}$ may be used at more than $100 \mathrm{~A}$ [33]. MOSFETs were used as key elements to operate at low voltages, high power levels and frequencies above $50-100 \mathrm{kHz}$. In particular, the IRL2505 model with a current of $74 \mathrm{~A}$ has a drain resistance - a leakage $R_{\mathrm{DS}}$ of $8 \mathrm{~m} \Omega$; model AUIRFS8409 with a voltage of $40 \mathrm{~V}$, at a current of $195 \mathrm{~A}$ has a resistance of $1.2 \mathrm{~m} \Omega$; and IRF2804S refers to $40 \mathrm{~V}, 320 \mathrm{~A}$, and $1.6 \mathrm{~m} \Omega[34,35]$.

Fig. $1, b$ shows the following: $V D_{1}-V D_{3}$ as Schottky diodes, $C_{1}-C_{2}$ as ionistors up to $4 \mathrm{~V}$, and $\mathrm{C}_{3}$ as a combined ionistor with consumer voltage. As to the $\mathrm{C}_{3}$ ionistor, it can be combined with several $2-4 \mathrm{~V}$ ionistors to obtain $12-24 \mathrm{~V}$. Given the ability of the MOSFET transistors to operate at high frequencies, a variant was developed to use for a $C_{3}$ pulse capacitor a type IKE-90/300 at $300 \mathrm{~V}, 2 \mathrm{~F}$ and IKE- $115 / 300$ at $300 \mathrm{~V}, 2.5 \mathrm{~F}$.

In the scheme under consideration, ionistors operate in difficult conditions if they are completely discharged and recharged at a certain frequency. This mode will complicate the operation of key elements. Therefore, a partial discharge mode was used and the residual charge would serve to limit peak currents. The frequency dependence on the residual 
voltage was obtained under the condition that unchanged energy was transmitted:

$$
f_{1} \frac{C U_{1}^{2}}{2}=f_{2} \frac{C\left(U_{1}-U_{2}\right)^{2}}{2}
$$

where $C$ is the capacity of the accumulator; $U_{1}$ and $U_{x}$ are maximum and residual charge and discharge voltages, respectively; $f_{1}$ is the frequency at full discharge of the capacitor; and $f_{2}$ is the frequency at partial discharge of the capacitance up to $U_{x}$.

The dependence of frequency on the degree of discharge of the capacitance was experimentally verified:

$$
f_{2}=\frac{f_{1} U_{1}^{2}}{\left(U_{1}-U_{x}\right)^{2}} ; \quad U_{x}=\frac{U_{1}}{n} ; f_{2}=f_{1} n^{2},
$$

where $n$ is the multiplicity of residual voltage. In practice, this means that the same energy can be transmitted at full capacity discharge at $50 \mathrm{~Hz}$ or partial discharge (1/3) at $450 \mathrm{~Hz}$. As the frequency increases, the residual charge increases, which will limit the current flow at the beginning of the ionistor charge process.

\section{3. Creation of a mathematical model of low voltage ionistor converter}

The following time structure was created. The process is divided into steps:

-1 - charge of ionistors in parallel switching;

-2 - break of a circle of a power supply with a key and recharging of the ionistors at the expense of inductive components;

- 3 - discharge of sequentially switched ionistors on storage capacity and load;

-4 - discharge capacity and load inductive components.

Let us denote this process as the first cycle. During the fourth step of the first cycle, the first step of the second cycle begins. Its difference depends on the presence of residual charges on the ionistors. The difference between cycles depends on the increase in residual charges. That is, the circuit is implemented when the initial conditions of the next step and the cycle are the final conditions of the previous one. A sign of a steady process is the stabilization of the output voltage.

The first step is the charge of the capacitor from the power supply in Fig. 2, where $G$ with a $4 \mathrm{~V}$ DC power source symbolizes a lithium battery consisting of one large capacity can. $K$ is the transistor key, $V D$ is the reverse diode, $r_{z}$ is the charging resistance, which includes: active resistance of the key, battery, inductance, and capacitance. $C$ is a charge capacitor (ionistor) consisting of a certain number of ionistors switched on in parallel.

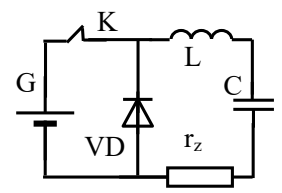

Fig. 2. Step 1. A charge circuit

This is a differential equation describing the process of charging ionistors from a chemical current source:

$$
U_{G}=L_{2} q^{\prime \prime}+r_{2} q^{\prime \prime}+\frac{q+q_{03}}{C},
$$

where $L_{z}$ and $r_{z}$ mean the total inductance and the resistance of the charging circuit; $C$ is the capacity when the batteries are switched on in a parallel mode and there is the corresponding number of capacitors; $q_{03}$ is the residual charge, which is zero for the initial process, and later it corresponds to the charge remaining from the third step.

In the received second-order differential equation, its initial conditions are the charge and the current at the time of the key $K$.

During the second step, there is the switch of the key $K$ (Fig. 3), and the ionistors are additionally charged in parallel switching due to the inductive components, through the reverse diode $V D$. As noted earlier, the conversion of direct current electrical energy occurs without the use of inductive elements. However, there may be times when high frequencies (as we also do not limit them) take into account the inductance of the connecting bus as well as the inductance of the chemical source and the ionistor. On the other hand, when operating at low frequencies, it is appropriate to introduce some inductance to limit the initial current surge. In both cases, the reverse diode $V D$ (Fig. 3) will give some energy boost. Its value is especially important when switching on high currents.

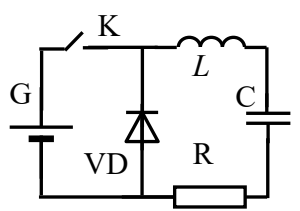

Fig. 3. Step 2. A discharge circuit

The differential equation describing this process with the initial current obtained from equation (3) at its final value for the first step and the additional charge obtained by working out the inductance of the reverse diode has the following form:

$$
L q^{\prime \prime}+R q^{\prime}-\frac{q+q_{01}}{C}=0,
$$

where $q_{01}$ is the charge accumulated at the time of switching in the previous step on the capacitor $C$.

The initial conditions for it are the charge $q_{0}$ and the current $i_{0}$ at the time of commutation. The solutions of equations (3) and (4) for the two variants are shown in Fig. 4. Position $a$ is the charging current, $c$ is the voltage on the capacitor, and $e$ is the working of the reverse diode.

The switching occurred at a falling current of $50 \mathrm{~A}$ at the time of $2 \cdot 10^{-3} \mathrm{~s}$ at a maximum voltage of $5 \mathrm{~V}$. In the second option, the switching occurred before $10^{-3} \mathrm{~s}$; the positions $b$, $d$, and $f$ correspond to the previous ones, but the switching occurred at a maximum current of $180 \mathrm{~A}$, with the voltage of $2.5 \mathrm{~V}$ and the resulting voltage of $2.6931 \mathrm{~V}$. In this case, twice the duration of the charge of $2 \cdot 10^{-3} \mathrm{~s}$ gave a voltage of $5 \mathrm{~V}$, against the duration of $10^{-3} \mathrm{~s}$ with a resulting voltage of $2.7 \mathrm{~V}$. That is, the efficiency of working the reverse diode at the current of $175 \mathrm{~A}$ (position $f$ ) is slightly smaller in voltage than in the first option. It is impossible to predict the effect of the frequencies, the charge and discharge ratio, and a number of other parameters. Only the study of the mathematical model of the converter can answer these questions. The next, third step (Fig. 5), describes the process of connecting the ionistors through sequential switching and their discharge on the storage capacity $C_{2}$ and loading $R_{L}$. 

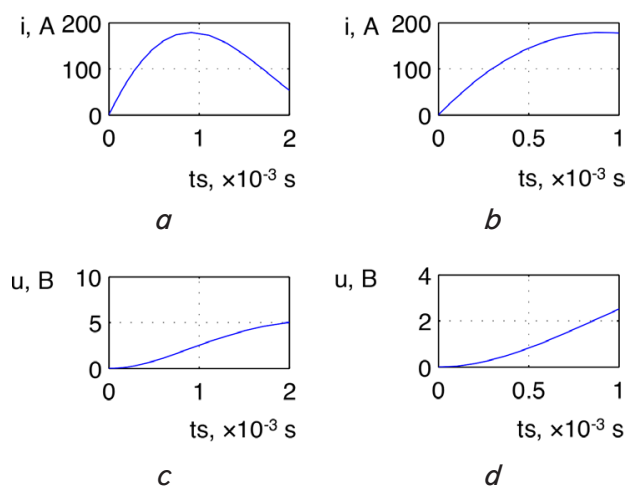

u, B
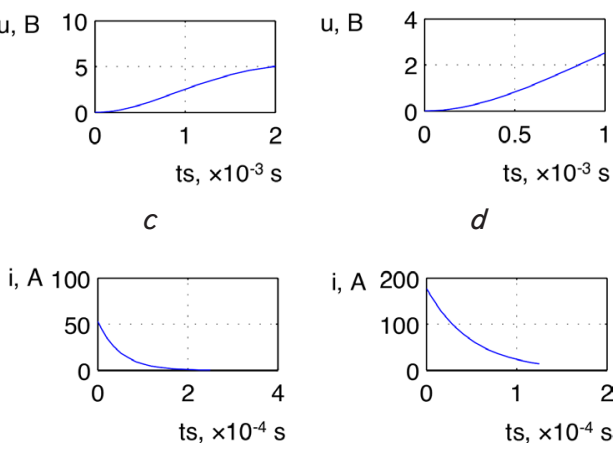

e

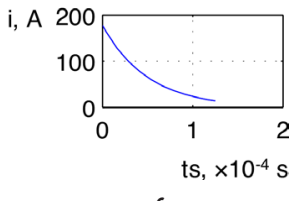

Fig. 4. The capacitor charge options: $a, c$, and $e-$ switching at falling current; $b, d$, and $f-$ at maximum current

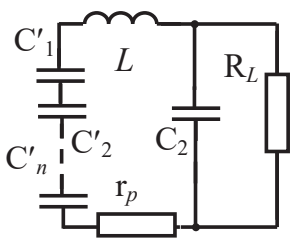

Fig. 5. Step 3. A consecutive discharge circle

We find the dependence of the output voltage $U_{2}$ on the number of ionistors $n$, their capacitance, and the value of the capacitor $C_{1-n}$ in series switching:

$$
U_{2}=\frac{q_{0}}{n \cdot \frac{C}{n^{2}}}=n \cdot \frac{q_{0}}{C}, \quad C_{1-n}=\frac{C}{n^{2}},
$$

where $q_{0}$ is the charge accumulated by the capacitors; $n$ is the number of capacitors.

In Fig. 5 , the capacitors $C_{1}-C_{n}$ symbolize a certain number of nominally identical serially switched ionistors, and $r_{p}$ is a bit resistance, which includes active resistance of ionistors, connecting buses, keys, similarly to inductances $L_{p} . C_{2}$ is the storage capacity, and $R_{L}$ is the active load. Let us develop a differential equation of the discharge circle of Fig. 5:

$$
\left\{\begin{array}{l}
\frac{q}{C_{1-n}}+L_{p} q^{\prime \prime}+r_{p} q^{\prime}-u_{2}=0, \\
q^{\prime}+C_{2} u_{2}+\frac{u_{2}}{R_{L}}=0 .
\end{array}\right.
$$

where $L_{p}$ and $r_{p}$ are the total active and inductive resistance of the discharge circuit, $u_{2}$ is the load voltage, and $R_{L}$ is active load.

It is more convenient to conduct tests when the system of differential equations results in an explicit form with respect to a previous derivative. After completing the standard transformations, we get the following:

$$
q^{\prime \prime \prime}=\frac{1}{L_{p} C_{2}}\left[\begin{array}{l}
-\left(r_{p} C_{2}+\frac{L_{p}}{R_{L}}\right) \cdot q^{\prime \prime}+ \\
+\left(\frac{C_{n}}{C_{1-n}}-\frac{r_{p}}{R_{L}}-1\right) \cdot q^{\prime}+\frac{1}{R_{L} C_{1-n}} \cdot q
\end{array}\right],
$$

Since we have a third-order differential equation, we determine the initial conditions $q_{0}, q_{0}^{\prime}, q_{0}^{\prime \prime}$. To find them, we should consider the following facts. At the time the keys are actuated, the current is zero. The initial charge on capacities $C_{1-n}$ is found as the sum of the charges of the first and second steps after integrating the current of the second step. The solution of equation (7) is presented in Fig. 6.

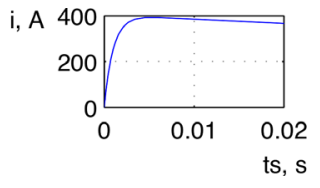

$a$

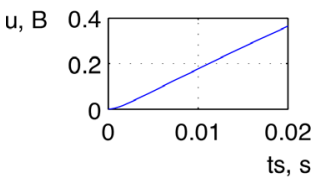

C

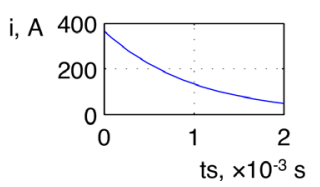

e

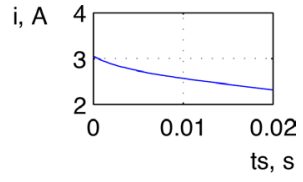

$b$

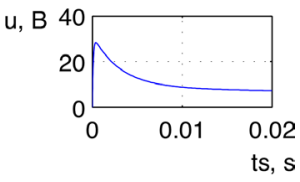

$d$

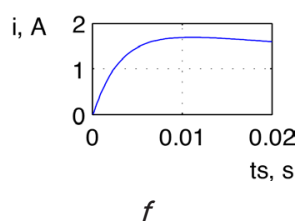

Fig. 6. Transients in the capacitors: $a, c$, and $e-$ a charge in a parallel mode; $b, d$, and $f-$ a discharge in a series

In order to show the different options, Fig. 6 presents the case when the capacity of the ionistors was increased to $20 \mathrm{~F}$. The first step, position $a$ : the charging current from the battery with a voltage of $4 \mathrm{~V}$, with the key actuation at $2 \cdot 10^{-2} \mathrm{~s}$, with a current of $350 \mathrm{~A}$. Position $c$ : the increase of voltage on the capacitor; voltage increases to $0.4 \mathrm{~V}$. Position $e$ : there is a charge current due to the reverse diode VD1 and inductance. Position $b$ : 8 capacitors $C$ are switched on in parallel to their switching to the serial connection (voltage increased 8 times), and there is discharge on the capacitor $C_{2}$. Position $d$ : there is a boost of the charge voltage of the current on the capacitor $C_{2}$. Position $f$ : voltage increases on the capacitor $C_{2}\left(\operatorname{load} R_{L}\right)$.

The fourth step of Fig. 7: the capacitor $C_{2}$ is charged due to the inductance and supply of the load $R_{L}$. Along with the fourth step, the first and second steps of the second cycle occur. That is, the duration of the fourth step corresponds to the sum of the durations of the first and second steps. At the time of switching $K_{2}$, the current retains its value and in some way is distributed between the capacitor and the load. We constructed the system of differential equations so that the current flowing to the capacitor could be removed and not searched separately. The initial condition is that the capacitor $C_{2}$ has a certain charge $q_{03}$ (from the third step). At the time of commutation in the circuit $L_{p}-C_{2}, R_{L}-r_{r}-V D$ there is the current $i_{03}$, which is defined as the end of the previous step. Also, according to the law of charge conserva- 
tion, the charge corresponding to the current at the moment of commutation is stored - that is, we have initial conditions for the charge, the current (the first derivative); in the future, we will find the second derivative. Below, there is a system of differential equations describing the above processes.

$$
\left\{\begin{array}{l}
L_{p} q^{\prime \prime}+r_{r} q^{\prime}-\frac{q_{c}-q_{03}}{C_{2}}=0 \\
q^{\prime}+q_{c}^{\prime}+\frac{q_{c}-q_{03}}{C_{2}}=0
\end{array}\right.
$$

where $q$ and $q$ ' are the charge and current traveling by inductance, diode, resistance $r_{r} ; q_{c}$ and $q_{c}^{\prime}$, are the charge and current passing through the capacitor $C_{2}$.

After completing the mathematical transformations, we obtain:

$$
q^{\prime \prime \prime}=\frac{1}{C_{2} L_{p}}\left[\left(\frac{L_{p}}{R_{H}}-C_{2} r_{r}\right) \cdot q^{\prime \prime}+\left(\frac{r_{r}}{R_{H}}-1\right) \cdot q^{\prime}\right],
$$

The initial conditions $q_{00}, q_{00}^{\prime}$, and $q_{00}^{\prime \prime}$ are taken from the final values of the previous equation (7); we find the initial conditions for the second derivative from the first equation of system (8); assuming that the current at the moment of switching is zero, we obtain the value of the second derivative as follows:

$$
q_{00}=-\frac{1}{L_{p}} \cdot\left(r_{r} \cdot i_{0}-u_{k}\right)
$$

where $\left(q_{c}-q_{02}\right) / C_{2}$ is the first equation of system (8); the voltage $\left(u_{k}\right)$ on the capacitor $C_{2}$, at the moment of commencement of the switching of the key, is defined as the final value from the previous equation. The change of the voltage is caused by the change of the electromotive force (EMF) direction on the inductance at the moment of switching. Such was the end of the first cycle, consisting of four steps.

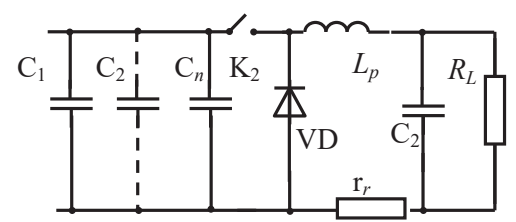

Fig. 7. Step 4. A discharge for the load

The connection of the steps in time is shown in Fig. 8; the load will always be voltage-carrying. In step 3 , there is a process of transition of charge from sequentially switched capacitors to the load, or when charging the capacitors under the voltage of the storage capacitor. Their total duration (frequency) and the ratio of the duration in the steps can vary widely.

Thus, we described the first cycle, which began at zero initial conditions both for the charge $q_{0}$ and the current $i_{0}$. The following cycles will be different from the previous number of accumulated charges. Determining the final voltage at the time of switching and knowing the capacity, we find the residual charge that meets the initial conditions of the next step. In the second and subsequent cycles, the differential equations that describe them remain unaltered; only the initial conditions change.

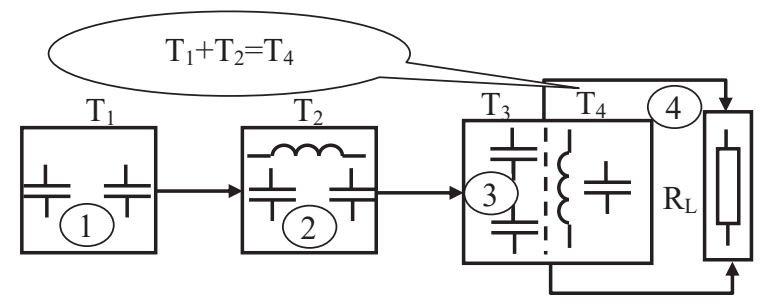

Fig. 8. The relationship of the step time in the cycle

Differential equation (9) is solved relative to the current due to the inductance; therefore, in the first cycle the voltage and current with the load have one direction. For subsequent cycles, when there is a charge on the capacitor $C_{2}$, the load is fed by the current from the capacitor $C_{2}$, and its direction is opposite to the direction of the charging current; that is, we have graphs of the voltage and currents of opposite polarities. The resultant solution of the 20th cycle for currents and voltages is shown in Fig. 9.

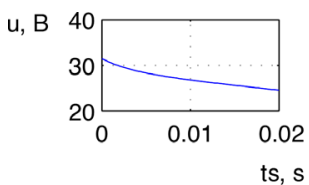

$a$

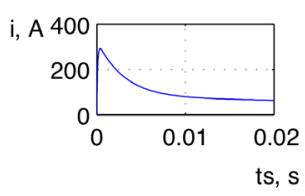

c

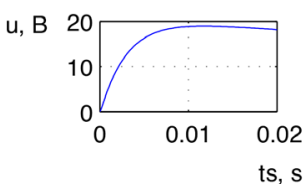

e

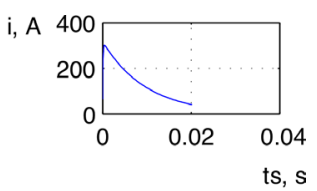

$b$

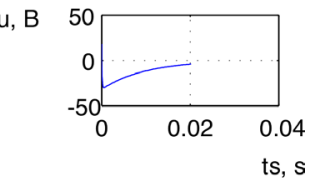

d

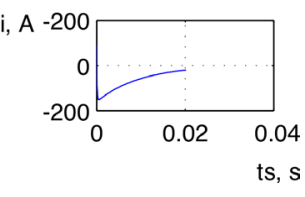

$f$
Fig. 9. The plots of the currents and voltages with the load; steps 3 and 4 of the 20th cycle: $a, c$, and $e$ are the processes on sequentially switched capacitors; $b, d$, and $f$ are the processes with loading

As the charge accumulates in cycles, the current and voltage on the load increase. The criterion when the device enters the steady state mode can be the condition when the difference of the end voltage of step 4 between the previous cycle and the next will not exceed the preset value $\Delta U$.

Using the capacitive converter shown in Fig. 1 provides for its work with electrochemical energy storage devices as part of the energy system, on electric vehicles, in conventional cars, and in other cases, where it is desirable to replace a certain number of elements with one equivalent in energy. Therefore, both the electrochemical elements and the ionistors can differ significantly in their parameters. Of course, in-field studies do not provide that amount of data. The obtained mathematical model makes it possible to study the work of the converter on a case-by-case basis. 
Such parameters as impedances of batteries, ionistors, and implementation of the element base of the converter can vary widely. They, in turn, will be correlated with the frequency, the ratio of the duration of the steps, and the power. Therefore, as a result of the study, we will draw graphs for one of the parameter combinations, when in steady state (cycle 50) the output voltage is approximately $100 \mathrm{~V}$ and the load has an active resistance of $0.2 \Omega$. Therefore, the output power is about $40 \mathrm{~kW}$. In Fig. 10, $a$, we observe the switching current of the ionistors after their discharge under load (in series connection) and the operation of the reverse diode of step 4 .

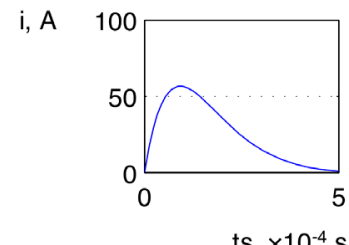

ts, $\times 10^{-4} \mathrm{~s}$

$a$

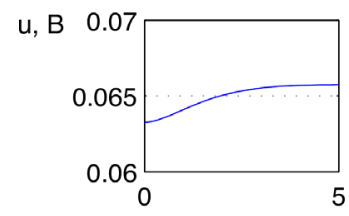

ts, $\times 10^{-4} \mathrm{~s}$

c i, A

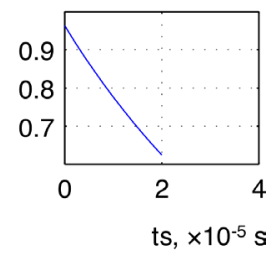

$b$

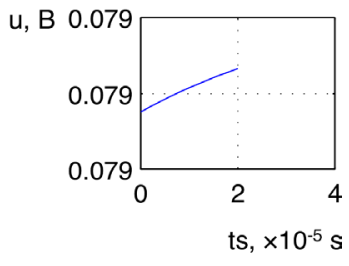

d
Fig. 10. Cycle 10; steps 3 and 4; voltage and currents under load: $a$ is step 3 , with current on the capacitor $C_{2}$ and the load; $b$ is step 4 , with current through the reverse diode; $c$ is step 3 , with voltage on the load and the capacitor; $d$ is voltage surge through the reverse diode

The current is continuous in Fig. 10, $a$, with the switching at $0.95 \mathrm{~A}$, and the beginning of the cycle of switching on the diode Fig. 10, $b$, also at the level of 0.95 A. Accordingly, with the voltage on the active load (Fig. 10,c) there is a voltage surge due to inductance from $0.07 \mathrm{~V}$ to $0.08 \mathrm{~V}$, Fig. 10, $d$.

Fig. 11 shows the operation of the converter in a steadystate mode, which happened during the 50th cycle. The processes occurring here are similar to those described above for Fig. 10, except for the increase of the current up to $150 \mathrm{~A}$ and the voltage up to $113 \mathrm{~V}$. The switching current does not interrupt in the region of $8 \mathrm{~A}$.

Operation of the reverse diode Fig. 11, $b$ changes the current at $0.5 \cdot 10^{-5} \mathrm{~s}$, but this means that it will close and the energy on the recharge will not be lost; it also prevents possible oscillatory processes. The load voltage in step 3 in Fig. 11, $c$ has a descending direction from $113.5 \mathrm{~V}$ to 113.4 V; during step 4, there is a surge of the voltage on the inductance (Fig. 11, d) from $113 \mathrm{~V}$ to $136 \mathrm{~V}$ due to the operation of the reverse diode. In total for 50 cycles in all 4 steps, there was no sign of violation of the law of switching, which confirms the reliability of the mathematical model of the processes of voltage conversion.

\section{Discussion of the results of studying the operation of the low-voltage DC converter}

The conducted tests on step-up serial DC-DC converters have shown that there are no converters with a power exceeding $200 \mathrm{~W}$ at an input voltage of up to $5 \mathrm{~V}$. Various circuits and technological techniques can somewhat extend the specified range [23]. In general, the problem is not resolved. The study has found that the main obstacle to increasing the power is a high-frequency power transformer. It is difficult to imagine what its design with a winding for currents of more than 200-300 A should be. The cooling conditions of both the core and the windings will be extremely unfavorable, with significant static and dynamic losses. Another problem is to overcome magnetic fluxes. One thing is the localization of the anti-electromotive force of scattering at currents up to $10-50 \mathrm{~A}$, and quite another if currents are above $100 \mathrm{~A}$. The energy that appears thus must be directed somewhere. All this complicates the scheme, reducing the efficiency. It is advisable to find a way to convert a constant voltage using only the electric field energy that can accumulate in the ionistors.

Using the method of parallel charge of ionistors, with their subsequent discharge in series helps avoid the intermediate conversion of electrical energy into magnetic field energy. Fig. 1 shows schematic solutions that implement the idea. Both in the transformer and in the ionistor converter there is an automatic stabilization of the output voltage when the load is changed due to the degree of discharge of the capacitor. This converter helps soften the work of key elements while increasing power. By increasing the cyclic frequency, the amplitude of the charge-discharge differential voltage decreases, and thus the current surges are reduced. However, at the same time, the 'energy' of the charges increases, and only the 'peaks' of the amplitudes of the currents work. The resulting dependence is represented in expressions (1) and (2).

The processes occurring in the converter are described by a series of differential equations that are related to the initial conditions. Such structure allows describing all dynamics of transient and steady processes under a change of the ratio of charge and discharge duration, values of parameters of chemical storage of electricity, ionistors, multiplicity of increase of voltage, and internal resistances of all elements. This means that according to the tasks set by simulation, it is possible to find the optimal ratio of parameters depending on the type of chemical storage and power for the consumer.

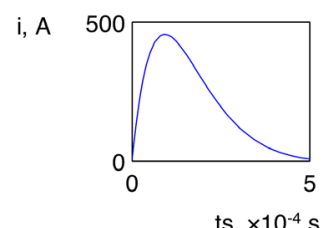

$a$

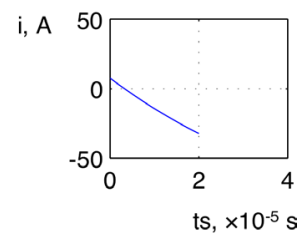

$b$

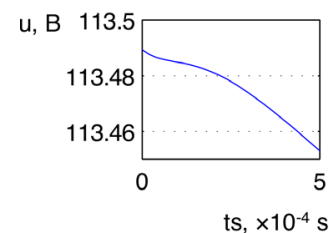

c

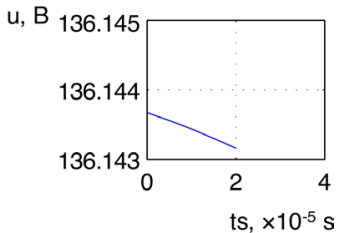

d

Fig. 11. Cycle 50; steps 3 and 4; voltage and currents under load: $a$ shows charging current on the storage capacity; $b$ is reverse diode current; $c$ is load voltage during step $3 ; d$ is load voltage in step 4 
Thus, Fig. 4 presents two variations of steps 1 and 2 of the first cycle. The first step is when the switching occurs at a current of $50 \mathrm{~A}$ (Fig. 4, $a$ ); on the reverse diode additional impulse $50 \mathrm{~A}$ (Fig. 4,e), we get a voltage of $4 \mathrm{~V}$ (Fig. 4, $c$ ). In the second variant, with a switching current of $150 \mathrm{~A}$ (Fig. 4, $b$ ) and a pulse through diode at $150 \mathrm{~A}$ (Fig. $4, f$ ), the voltage will be only $2 \mathrm{~V}$ (Fig. 4, $d$ ). Which of the options is preferable is unclear as it depends on many parameters. By performing simulations for a specific accumulator type and ionistor, in a steady state, it is possible to determine the optimal ratio. Thus, Fig. 11 shows the 50th cycle diagrams (steady state), with the voltage and the current on load. Voltage ripples are insignificant, due to the large capacity at a charging current of $450 \mathrm{~A}$.

Using the specific properties of ionistors and chemical energy storage devices, taking into account their parameters, and researching the model of an ionistor converter, we can build a low-voltage converter of the required power. Its features are the absence of a transformer and the ability to operate at voltages less than $5 \mathrm{~V}$, at currents greater than $100 \mathrm{~A}$. This will reduce the number of elements in the battery for power storage systems.

The study did not solve the optimization problem of the influence of the ratios of the duration of the cycle, the duration of the cycle, the multiplicity of voltage increase, capacitor values, and more.

Further research must help find the correspondence between the pairs of battery types - the type of ionistors, determining their frequency parameters. The next step is to solve an optimization problem, where the generalized criterion can be the power, the voltage level or the efficiency. After this solution, it is possible to obtain the optimal frequency, the ratio of the steps, and the value of the capacitors. A certain number of elements are replaced by one equivalent in power. Probably one of the problems is to determine the frequency of an ionistor operation, with its partial discharge, and there is no other than the experimental path.

\section{Conclusion}

1. It is not advisable to create a DC-DC boost converter with voltages below $5 \mathrm{~V}$ and a power exceeding $1 \mathrm{~kW}$. At currents above $200 \mathrm{~A}$, problems arise in cooling the windings and the transformer core. Additional measures must be taken to localize the anti-electromotive force of the magnetic field scattering.

2. It is advisable to carry out the direct conversion of low-voltage DC energy without converting it into magnetic field energy, using a parallel charge of subsequent ionistor discharge in a sequential mode.

3. A mathematical model was obtained for processes occurring in an ionistor converter. It helped find acceptable modes of its operation, depending on the type of chemical energy storage, power of the consumer, and the output voltage. This will allow, instead of a certain number of elements of the chemical energy storage, to use one that would be equivalent in energy.

\section{References}

1. Li, X., Zhang, D. (2018). Coordinated Control and Energy Management Strategies for Hundred Megawatt-level Battery Energy Storage Stations Based on Multi-agent Theory. 2018 International Conference on Advanced Mechatronic Systems (ICAMechS). doi: https://doi.org/10.1109/icamechs.2018.8506868

2. Badeda, J., Kwiecien, M., Schulte, D., Ruwald, T., Sauer, D. U. (2017). Adaptive battery steering and management system for the optimized operation of stationary battery energy storage systems in multi-use applications. 2017 IEEE International Telecommunications Energy Conference (INTELEC). doi: https://doi.org/10.1109/intlec.2017.8214149

3. Smith, S., Firdous, I., Wang, Q., Esmalla, S., Daoud, W. A. (2019). A two-dimensional model of the vanadium-cerium redox flow battery. Electrochimica Acta, 328, 135019. doi: https://doi.org/10.1016/j.electacta.2019.135019

4. Wang, R., Li, Y., Wang, Y., Fang, Z. (2020). Phosphorus-doped graphite felt allowing stabilized electrochemical interface and hierarchical pore structure for redox flow battery. Applied Energy, 261, 114369. doi: https://doi.org/10.1016/j.apenergy.2019.114369

5. Grisales-Noreña, L. F., Montoya, O. D., Gil-González, W. (2019). Integration of energy storage systems in AC distribution networks: Optimal location, selecting, and operation approach based on genetic algorithms. Journal of Energy Storage, 25, 100891. doi: https://doi.org/10.1016/j.est.2019.100891

6. Iurilli, P., Brivio, C., Merlo, M. (2019). SoC management strategies in Battery Energy Storage System providing Primary Control Reserve. Sustainable Energy, Grids and Networks, 19, 100230. doi: https://doi.org/10.1016/j.segan.2019.100230

7. Biya, T. S., Sindhu, M. R. (2019). Design and Power Management of Solar Powered Electric Vehicle Charging Station with Energy Storage System. 2019 3rd International Conference on Electronics, Communication and Aerospace Technology (ICECA). doi: https://doi.org/10.1109/iceca.2019.8821896

8. Abdelkafi, A., Masmoudi, A., Krichen, L. (2018). Assisted power management of a stand-alone renewable multi-source system. Energy, 145, 195-205. doi: https://doi.org/10.1016/j.energy.2017.12.133

9. Khan, A., Memon, S., Sattar, T. (2017). Integration and Management of Solar Energy for Electric Vehicle Charging Station. Proceedings of SWC2017/SHC2017. doi: https://doi.org/10.18086/swc.2017.16.03

10. Zhang, Y., Lu, S. (2018). Research on Series-Parallel Connection Switching Charging Method for Lithium Battery of Autonomous Underwater Vehicles. 2018 IEEE 8th International Conference on Underwater System Technology: Theory and Applications (USYS). doi: https://doi.org/10.1109/usys.2018.8779098

11. Belmokhtar, K., Ibrahim, H., Ghandour, M. (2016). Improving performance of batteries by using charge equalization systems - Experimental validation. 2016 3rd International Conference on Renewable Energies for Developing Countries (REDEC). doi: https:// doi.org/10.1109/redec.2016.7577542

12. Vodorodnaya energetika: nachalo bol'shogo puti. Available at: https://habr.com/ru/company/toshibarus/blog/428511/ 
13. Korovin, N. V. (2005). Toplivnye elementy i elektrohimicheskie energoustanovki. Moscow: Izd-vo MEI, 208.

14. Akkumulyatory gelevye, mul'tigelevye i AGM - v chem raznitsa? Available at: https://lantorg.com/article/akkumulyatory-gelevyemultigelevye-i-agm-v-chem-raznitsa

15. Korovin, N. (2002). Nikel'-Metallgidridnye akkumulyatory. Elektronnye komponenty, 4, 99-103.

16. Revolyutsiya zakonchilas'. Est' li al'ternativa litiy-ionnomu akkumulyatoru? Available at: https://habr.com/ru/company/toshibarus/blog/462185/

17. Stoimost' soderzhaniya i remonta elektrokara Nissan LEAF v Ukraine. Available at: https://elektrovesti.net/60052_stoimost-soderzhaniya-i-remonta-elektrokara-nissan-leaf-v-ukraine

18. Savinyh, V. (2018). «Salyut-7». Zapiski s «mertvoy» stantsii. Moscow: Eksmo, 256.

19. Sidorovich, V. (2017). K voprosu utilizatsii litiy-ionnyh akkumulyatorov. Available at: https://renen.ru/on-the-issue-of-recycling-lithium-ion-batteries/

20. Povyshayushchie DC-DC preobrazovateli. Available at: https://bigl.ua/sc-2508878-Povyshayuschie-dc-dc-preobrazovateli?gclid= Cj0KCQiAl5zwBRCTARIsAIrukdPxFVpQB7Wt12gea7RxyOYPa4sPn-8d9EL43rXdajAdkeURDetWB58aAnvDEALw_wcB

21. DC/DC-преобразователи мощностью 1 кВт серии FXW от Calex. Available at: https://power-e.ru/components/dc-dcpreobrazovateli-moshhnostyu-1-kvt-serii-fxw-ot-calex/

22. GaN used to Design 2.5MHz3kW Resonant DC-DC (2016). Available at:https://www.radiolocman.com/news/new.html?di=276561

23. Tsarenko, A., Seregin, D. (2006). K voprosu postroeniya moshchnyh DC-DC preobrazovateley napryazheniya, pitayushchihsya ot nizkovol'tnyh setey. Silovaya Elektronika, 3, 68-72.

24. Loo, S., Keller, K. (2004). Single-cell Battery Discharge Characteristics Using the TPS61070 Boost Converter. Application Report SLVA194-AUGUST 2004. Available at: http://www.ti.com/lit/an/slva194/slva194.pdf

25. Sozdanie vysokoeffektivnyh kompaktnyh preobrazovateley postoyannogo napryazheniya dlya perenosnoy apparatury, pitaemoy ot odnogo 1,5V elementa. Available at: http://www.gaw.ru/html.cgi/txt/publ/powersuply/bat_1-5.htm

26. Vasil'ev, A. (2014). Kondensator vmesto akkumulyatora. Available at: https://www.elec.ru/articles/kondensator-vmestoakkumulyatora/

27. Den'shchikov, K. K. (2013). Superkondensatory: printsip postroeniya, tehnika i primeneniya. Uchenyy sovet OIVT RAN.

28. Oakes, L., Westover, A., Mares, J. W., Chatterjee, S., Erwin, W. R., Bardhan, R. et. al. (2013). Surface engineered porous silicon for stable, high performance electrochemical supercapacitors. Scientific Reports, 3 (1). doi: https://doi.org/10.1038/srep03020

29. Yan, X., Tai, Z., Chen, J., Xue, Q. (2011). Fabrication of carbon nanofiber-polyaniline composite flexible paper for supercapacitor. Nanoscale, 3 (1), 212-216. doi: https://doi.org/10.1039/c0nr00470g

30. Pentegov, I. V. (1996). K teorii teslovskih protsessov zaryadki emkostnyh nakopiteley energii. Elektrichestvo, 6, $42-47$.

31. Despotuli, A. L., Andreeva, A. V. (2003). Sozdanie novyh tipov tonkoplenochnyh superkondensatorov dlya mikrosistemnoy tehniki i mikro- (nano) elektroniki. Mikrosistemnaya tehnika, 11, 2-10.

32. Despotuli, A. L., Andreeva, A. V., Vedeneev, V. V., Aristov, V. V., Mal'tsev, P. P. (2006). Vysokoemkie kondensatory dlya ul'traplotnogo poverhnostnogo montazha. Nano- i mikrosistemnaya tehnika, 3, 30-37.

33. Medzhahed, D., Tsvetkov, D. (2009). «Ideal'nye diody» ot kompanii STMicroelectronics. Novosti elektroniki, 14, $23-25$.

34. Nizkovol'tnye MOSFETs dlya sil'notochnyh primeneniy i zhestkih usloviy (2014). Available at: https://www.compel.ru/lib/65023

35. Bashkirov, V. (2008). Novye semeystva vysokoeffektivnyh nizkovol'tnyh MOSFET. Novosti elektroniki, 18, 29-32. 